\title{
Seasonal development of ozone-induced foliar injury on tall milkweed (Asclepias exaltata) in Great Smoky Mountains National Park
}

\author{
Lara Souza $^{\mathrm{a}, *}$, Howard S. Neufeld ${ }^{\mathrm{a}}$, Arthur H. Chappelka ${ }^{\mathrm{b}}$, \\ Kent O. Burkey ${ }^{\mathrm{c}}$, Alan W. Davison ${ }^{\mathrm{d}}$ \\ ${ }^{a}$ Department of Biology, 572 Rivers Street, Appalachian State University, Boone, NC 28608, USA \\ ${ }^{\mathrm{b}}$ School of Forestry and Wildlife Sciences, $108 \mathrm{M}$ White-Smith Hall, Auburn University, Auburn, AL 36849, USA \\ ${ }^{\mathrm{c}}$ US Department of Agriculture, Agricultural Research Service, Plant Science Research Unit and Department of Crop Science, \\ North Carolina State University, 3908 Inwood Road, Raleigh, NC 26703, USA \\ ${ }^{\mathrm{d}}$ School of Biology, Ridley Building, University of Newcastle, Newcastle Upon Tyne, NE1 7RU, UK
}

Received 15 December 2004; accepted 2 July 2005

Leaf loss was not necessarily accompanied by symptoms of foliar ozone injury.

\begin{abstract}
The goals of this study were to document the development of ozone-induced foliar injury, on a leaf-by-leaf basis, and to develop ozone exposure relationships for leaf cohorts and individual tall milkweeds (Asclepias exaltata L.) in Great Smoky Mountains National Park. Plants were classified as either ozone-sensitive or insensitive based on the amount of foliar injury. Sensitive plants developed injury earlier in the season and to a greater extent than insensitive plants. Older leaf cohorts were more likely to belong to high injury classes by the end of each of the two growing seasons. In addition, leaf loss was more likely for older cohorts (2000) and lower leaf positions (2001) than younger cohorts and upper leaves, respectively. Most leaves abscised without prior ozone-like stippling or chlorosis. Failure to take this into account can result in underestimation of the effects of ozone on these plants.
\end{abstract}

(C) 2005 Elsevier Ltd. All rights reserved.

Keywords: Tall milkweed; Asclepias exaltata; Foliar injury; Ozone; Great Smoky Mountains National Park; Gas exchange; Anti-oxidants

\section{Introduction}

The southeastern United States often experience high ozone concentrations during the summer, despite relatively low population densities and lack of a heavy industrial base (McLaughlin and Downing, 1985; US EPA, 1996; Skelly et al., 1997). Long range transport, either from the industrialized upper midwest or the southwest US (TX and LA, for example), brings pollutant precursors into the region (National

\footnotetext{
* Corresponding author. Department of Ecology and Evolutionary Biology, University of Tennessee, 1416 Circle Drive, Knoxville, TN, USA. Tel.: +1 86597442 48; fax: +1 8659743067 .

E-mail address: 1souza@utk.edu (L. Souza).
}

Research Council, 1991; Dattore et al., 1991; Chameides and Cowling, 1995). When combined with high amounts of nitric oxides and volatile organic compounds (Krupa and Manning, 1988; Kang et al., 2001), not to mention the most number of stagnant air masses in the United States (Mueller, 1994), the result is unusually high ozone exposures during the growing season.

Great Smoky Mountains National Park (GRSM), located in the Southern Appalachian Mountains, is the most visited national park in the United States $(>9$ million visits in 1990; Shaver et al., 1994) and has been designated as an International Biosphere Reserve and World Heritage Site due to the diversity of its flora and fauna. The Park is threatened by a variety of biotic and abiotic factors, including 
exotic, invasive species and air pollution in the form of acidic deposition and gaseous pollutants, of which ozone is the most important. Although ozone concentrations have declined nationally by approximately $20 \%$ over the past 20 years (US EPA, 2001), southern and north-central regions have shown increases in the past decade, and GRSM is one of several national parks in which ozone exposures have significantly increased, nearly doubling between 1990 and 1999 (US EPA, 2001).

The National Park Service (NPS) is required to investigate and protect resources from any deleterious effects due to a deterioration in air quality as part of their mandate as a Class I area (Department of Interior, 1982). Toward this end, the NPS has sponsored air quality effects research in GRSM since 1987. Results of these investigations have shown that over 95 species of plants exhibit putative ozone symptoms in field situations (Neufeld et al., 1992), and these symptoms could be reproduced on at least 27 of 39 species exposed to elevated ozone in open-top chamber systems (Heagle et al., 1973). Of these species, the perennial herbaceous plant, tall milkweed (Asclepias exaltata L.), was one of the most sensitive to the effects of ozone. In the open-top chamber experiments of Neufeld et al. (1992), foliar symptoms and premature leaf senescence consistent with ozone exposure were found on tall milkweed plants in every ozone exposure treatment except charcoal-filtered.

Native plants can be useful as bioindicators (Bennett and Stolte, 1985; Manning, 1993; Blum et al., 1997; Manning et al., 2002) or detectors, sensu Manning (1993) in remote areas where there are no active ozone monitors (Bytnerowicz et al., 1993; Heagle et al., 1995, Chappelka et al., 1997). In GRSM, there are only six active monitoring sites to cover an area of more than 200,000 ha. Therefore, increased knowledge of the responses of bioindicators to ozone will be useful for characterizing ozone exposures in remote areas in the Park, as well as for determining the potential impacts ozone may be having on native plants.

Tall milkweeds are particularly suited as bioindicators of ozone air pollution because of their sensitivity to the pollutant (Bennett and Stolte, 1985; Neufeld et al., 1992; Chappelka et al., 1997) and their widespread distribution (at least at higher elevations in the Park). The species commonly occurs in partial shade within forest understories and along roadsides, and is widely distributed throughout the eastern US. In fact, its geographic distribution (USDA Plants Database, 2003) coincides closely with regions of relatively high ozone in the eastern US (US EPA, 1996). Plants growing in areas with higher light exposure are usually larger and more robust than those in partial shade (personal observation).

Although it is known that tall milkweeds are very sensitive to ozone (Neufeld et al., 1992; Chappelka et al., 1997), there is little information available on foliar injury development through time. In addition, we know little about the variation in foliar injury (i.e., stipple, chlorosis) among leaves on individual plants, or the factors responsible for variation in symptom development among individuals. Most field-based studies have been conducted only once or twice at the end of a season and have assessed injury as a function of the seasonal cumulative ozone exposure (Anderson et al., 1988; Heagle, 1994; Hildebrand et al., 1996). For example, Chappelka et al. (1997) measured foliar injury two times in early- to late August. Such data do not allow the determination of threshold exposures necessary to elicit foliar symptoms (Ghosh et al., 1998). Even so, Chappelka et al. (1997) did find that injury progressed rapidly over a short time period in August, with the percentage of injured leaves increasing from 63 to $79 \%$ in just 2 weeks. They also showed that up to $79 \%$ of individual tall milkweeds at Mt. Sterling Gap in GRSM could be classified as sensitive to ozone based on symptom development late in the season, supporting the hypothesis that genetic variation within the population exists in response to ozone.

We studied the same population group of tall milkweeds at Mt. Sterling Gap, GRSM that was investigated by Chappelka et al. (1997) with the goals of this study to follow foliar injury development on individual plants throughout entire growing seasons on a leaf-by-leaf basis and, to develop ozone exposure relationships for cohorts of leaves and individual plants, including threshold responses for injury development. By following all leaves from the time prior to any observed injury, until late in the season when many of the leaves had senesced, we could avoid the problem of underestimating ozone-induced foliar injury due to premature leaf loss (Ghosh et al., 1998; Bergweiler and Manning 1999).

\section{Materials and methods}

\subsection{Study site}

Our study was conducted at Mt. Sterling Gap, GRSM, North Carolina $\left(35^{\circ}, 42 \mathrm{~min}, 01 \mathrm{~s}, \mathrm{~N}\right.$ latitude; $83^{\circ}, 05 \mathrm{~min}, 52 \mathrm{~s}, \mathrm{~W}$ longitude), at approximately $1525 \mathrm{~m}$ elevation within a second growth forest consisting of mostly northern hardwoods (Whittaker, 1956). These forests dominate the middle to upper elevations from 1100 to $1500 \mathrm{~m}$ in GRSM and are characterized by sugar maple (Acer saccharum Marsh.), American beech (Fagus grandifolia Ehrhart.), and yellow birch (Betula lutea Michaux).

\subsection{Ozone measurements}

Ozone concentrations were measured to develop relationships between ozone exposure and foliar responses. Average ozone concentrations were calculated on a weekly basis for the summer of 2000 and biweekly in 2001 using passive ozone samplers (Ogawa \& Co., Inc., Pompano Beach, FL). These passive samplers collect ozone onto a filter coated with the absorbent sodium nitrite (Koutrakis et al., 1993; Yuska et al., 2003). During both years, monitoring began in May and continued through early October. Ozone was sampled at $2 \mathrm{~m}$ above the forest floor in both years, and additionally at $0.5 \mathrm{~m}$ in 2001 at two closely spaced locations ( $75 \mathrm{~m}$ apart) at Mt. Sterling Gap. Reported ozone values for 2001 are the average of these two locations. The passive sampler filters were retrieved and mailed to the Research Triangle Institute (RTI, NC) for analysis at the end of each sampling period. Ozone concentrations were measured weekly from June 5 to August 26 in 2000 and biweekly from May 15 to August 7 in 2001.

\subsection{Foliar surveys for ozone-induced injury}

In late May of 2000 and 2001, tall milkweed individuals were marked with plastic tagging at the base of the stem and numbered accordingly. Tall milkweed plants produce vertical rhizomes from which multiple stems can arise. 
However, only a single stem per individual was marked and surveyed. Ninetyfive individuals were randomly selected for foliar surveys at Mt. Sterling Gap for each of the summers of 2000 and 2001, respectively. Except for a small set of plants collected for greenhouse work, plants in 2001 were the same individuals as those surveyed in 2000. Surveys were conducted twice a month each summer from mid-May through August to assess the seasonal development of ozone-induced foliar injury. Plants averaged 2-4 leaf sets (tall milkweed plants have opposite leaves) in mid-May, while by the end of the season most individuals had anywhere from 4 to 7 leaf sets and ranged in height from 40 to $95 \mathrm{~cm}$. Surveys were terminated when most of the sensitive plants had lost a majority of their leaves, but prior to the onset of natural fall senescence, which at this high elevation can begin at the end of August for plants in the understory.

The percent leaf area that was chlorotic, stippled, necrotic, or was missing was evaluated for every leaf. Since necrosis and leaf area missing never amounted to more than $1 \%$ of the total leaf area, they were not included in further analyses. A modified Horsfall-Barratt scale (Horsfall and Barratt, 1945) was utilized to evaluate percent leaf area expressing typical ozone symptoms $(0 \%=1,1-6 \%=2,7-25 \%=3,26-50 \%=4,51-75 \%=5$, $76-100 \%=6$ ). Values were averaged for both leaves in a leaf set, and the means used for all further analyses.

In 2000, individuals from Mt. Sterling Gap were rated as being either sensitive or insensitive based on the amount of ozone-induced foliar injury, as well as amount of premature leaf loss. Plants with greater than level 3 (26-50\%) stippling or completely senesced leaves (but only those leaves with a prior history of ozone injury), were classified as sensitive, while those with less than level 3 injury were classified as insensitive. This designation occurred in early August before any obvious signs of senescence were observed in any of the other understory herbs.

Percent injured plants, leaves and leaf loss for insensitive and sensitive individuals were calculated for the population as a whole in both 2000 and 2001. At each leaf position, the mean percent of the leaf area with stippling and chlorosis was calculated for both sensitivity classes across either all leaves (injured and noninjured) or only for injured leaves. Finally, at the end of both growing seasons, the percent leaf loss for each leaf position was evaluated for both sensitivity classes. Abscised leaves were separated according to whether or not they showed prior instances of ozone-like symptoms (i.e. stippling or chlorosis).

Percent stippling and chlorosis were then plotted as functions of ozone exposure (SUM00 index) by leaf cohorts. A leaf cohort was defined as a set of leaves with a common date of origin. In 2000, many plants already had three leaf sets by the first survey date, while a few had four or even five leaf sets. On the first sampling date (June 5) we assumed that the most recent leaf on each plant had been produced the previous week (May 29). This meant that leaves in this cohort could have come from leaf positions $3-5$, depending on the plant.

Based on plant growth rates (about 7 days per leaf set), an estimate was made of the dates of origin for the next two oldest sets of leaves on all plants. This resulted in an origination date for cohort one of May 16, and for cohort 2 of May 22. For later surveys, the date of origin for a cohort was assumed to be half way between the sampling intervals in which it first appeared. Only leaf cohorts $1-5$ were analyzed because few plants produced more than this number of leaves and statistical analyses were therefore not possible for higher cohorts. A similar protocol was adopted in 2001, but cohort 1 was estimated to have originated the week prior to the installment of the passive samplers. We used the mean ozone exposure for April from a nearby site (Purchase Knob, NC, $\sim 15 \mathrm{~km}$ away) to get an estimate of the amount of ozone this cohort may have been exposed to during its first week of existence. Dates of origination for cohorts 1-5 in 2001 were April 24, May 1, May 8, May 22 and May 29.

We defined a threshold exposure for injury as that SUM00 exposure where more than $5 \%$ of the leaves in a cohort showed level $3(7-25 \%)$ injury or greater. Sometimes the observed injury increased from less than $5 \%$ to more than $5 \%$ from one survey to the next. When that happened, the threshold SUM00 for inducing injury was the calculated exposure midway between the two sampling times.

Plants were measured for growth (height) and flower production (biweekly) throughout the growing season whenever foliar surveys were done. Light readings were obtained at three times during the season (June, July and August) using a Li-Cor 190SA quantum sensor (Li-Cor, Inc., Lincoln, NE) connected to a Li-Cor 6200 photosynthesis system and photosynthetically active radiation (PAR) was measured several times during each day on a subsample of plants consisting of both sensitive and insensitive individuals.

\subsection{Statistical analyses}

Differences among leaf sets for within-population parameters such as percent of leaf area injured, were assessed using forward selection logistic regression and the Wald statistic (Agresti, 1996). Prior to analysis, all HorsfallBarratt ratings (the midpoint of each class) were converted to their mean percent injury and analyses conducted on the means. Because of the large number of zero data, and an inability of the models to accurately predict the probability of injury when a multinomial model was used, injury data were reduced to two categories: low injury (up to $16 \%$ injury, or class 3 ) and high injury ( $>16 \%$ ). Uninjured leaves were left out of the model. Season was divided into an early (up to Julian date 202) and late (after Julian date 202) period. Predictors of injury were leaf cohort, position, ozone and year. Insensitive plants were not analyzed because the levels of injury were so low (by definition) that no models could be found that resulted in good fits. However, since insensitive plants are defined by the degree of ozone-induced foliar injury observed, they are by default significantly different from the sensitive plants. Leaf loss was also reduced into two categories: no loss and at least one loss in order to increase the predictability of our model. The two categories for leaf loss referred to the whole individual plant and not to an individual leaf. Significant predictors for leaf loss in 2000 were leaf cohort and ozone, whereas in 2001, leaf position and ozone were retained in the model as predictors for leaf loss. A $t$-test was used to test for any difference in height growth between sensitive and insensitive individuals.

\section{Results}

\subsection{Ozone exposure}

The SUM00 indices were similar for both years: $113.6 \mathrm{ppm} \mathrm{h}$ and $102.5 \mathrm{ppm} \mathrm{h}$ in 2000 and 2001, respectively (Fig. 1). Exposures at $0.5 \mathrm{~m}$ (within the canopy) in 2001 were consistently lower then those at $2 \mathrm{~m}$ above the canopy by approximately $14 \%$ (data not shown).

We compared the ozone from the passive samplers to that obtained from the closest, active monitor, a state-maintained station located at Purchase Knob, in North Carolina (35 $35^{\prime} 17^{\prime \prime} \mathrm{N}, 83^{\circ} 04^{\prime} 52^{\prime \prime} \mathrm{W}, 1500 \mathrm{~m}$ elevation). This monitor is $13 \mathrm{~km}$ from our Mt. Sterling site, but at nearly the same elevation. We corrected our ozone indices for missing hours according to Lee et al. (1991), which resulted in 5\% and $7.3 \%$ corrections for 2000 and 2001, respectively. The $24 \mathrm{~h}$ SUM00 s (May 1 to September 30) were within $1.5 \%$ of each other for the two years (Table 1), while the $24 \mathrm{~h}$ seasonal means were essentially identical $(50 \mathrm{ppb})$. However, there were $10 \%$ more hours with ozone $\geq 60 \mathrm{ppb}$ in 2000 than 2001 and as a result, the $24 \mathrm{~h}$ SUM60 was $12 \%$ higher also. There were only $3 \mathrm{~h}$ greater than $100 \mathrm{ppb}$ in 2000, and none in 2001. Our passive samplers also showed higher SUM00 values in 2000 than 2001, but the absolute values were substantially reduced compared to the active monitor, most likely from differences in the timing of sensor placement, geographic variability in ozone concentrations within the Park, and canopy depletion, which can be up to $50 \%$ in these closed hardwood forests (Neufeld et al., 1992).

Rainfall data (Fig. 2a,b) from the nearest weather station at Waterville, NC (12 km away, and $1085 \mathrm{~m}$ lower in elevation, 


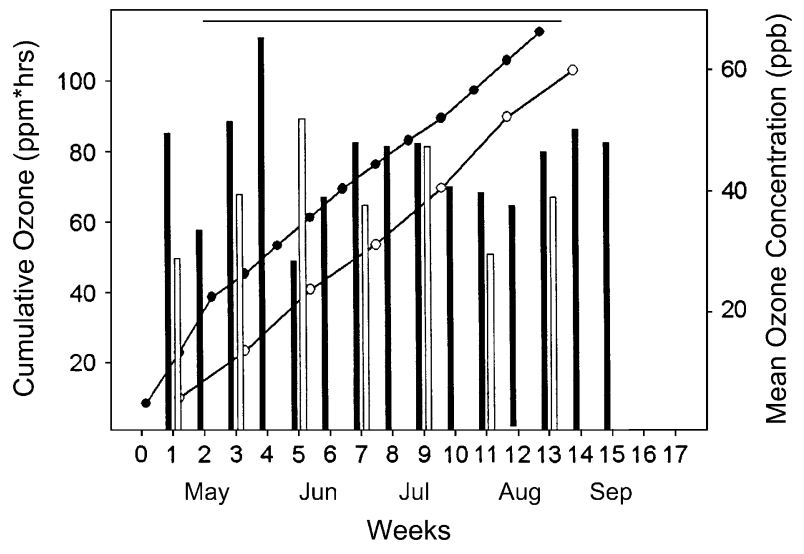

Fig. 1. Cumulative ozone in ppm h at Mt. Sterling Gap, NC (2000, filled circles; 2001, open circles) and weekly averages of ozone concentration in ppb (2000, filled bars) and biweekly (2001, open bars). Horizontal bar indicates time of year when foliar surveys were conducted.

$35^{\circ} 46^{\prime} \mathrm{N}, 83^{\circ} 06^{\prime} \mathrm{W}$ ) indicates that precipitation during the growing season May through October was $12 \%$ less in 2001 $(70.4 \mathrm{~cm})$ compared to $2000(79.7 \mathrm{~cm})$. These values are $31 \%$ (2000) and 16\% (2001) above the long-term normals for that station. There were no distinctive periods of drought in either year, with the longest dry period (which occurred once in both years) lasting for 9 days. There were more dry periods lasting six or more days in 2001 (8) than in 2000 (3). Temperature trends for mean maximum values did not depart from the long-term normals by more than $5 \%$ in either year (National Climatic Data Center, 2003). There were no differences in the frequency distribution of PAR between ozone-sensitive and insensitive individuals at the Mt. Sterling Gap (Souza, 2003), indicating that sensitivity in the field was not a result of plants growing in different light environments.

\subsection{Growth and foliar injury}

There were no differences in height between ozone-sensitive and insensitive plants in either $2000(43 \mathrm{~cm}$ vs $48 \mathrm{~cm}$, respectively; $p=0.667$ ) or 2001 ( $46 \mathrm{~cm}$ vs $40 \mathrm{~cm}$, respectively; $p=0.096$ ).

After an initial period where no ozone-induced injury was found, the percent of symptomatic sensitive plants increased linearly with time in both years. However, for insensitive individuals, the appearance of ozone-induced symptoms began later in the season, and the rate of increase in the percent of symptomatic plants, once it began, was higher (Fig. 3). Sensitive individuals began showing ozone-induced foliar injury earlier in the season (mid-June) when compared to insensitive individuals (late July/early August, see Fig. 3a,b), especially in

Table 1

Comparison of ozone indices at Purchase Knob, NC for years 2000 and 2001

\begin{tabular}{lllll}
\hline Year & $\begin{array}{l}\text { SUM00 } \\
(\mathrm{ppm} \mathrm{h})\end{array}$ & $\begin{array}{l}\text { SUM60 } \\
(\mathrm{ppm} \mathrm{h})\end{array}$ & $\begin{array}{l}\text { N60 } \\
\text { (no. of hours) }\end{array}$ & $\begin{array}{l}\text { N100 } \\
\text { (no. of hours) }\end{array}$ \\
\hline 2000 & 185.6 & 63.9 & 929 & 3 \\
2001 & 182.7 & 56.9 & 843 & 0 \\
\hline
\end{tabular}

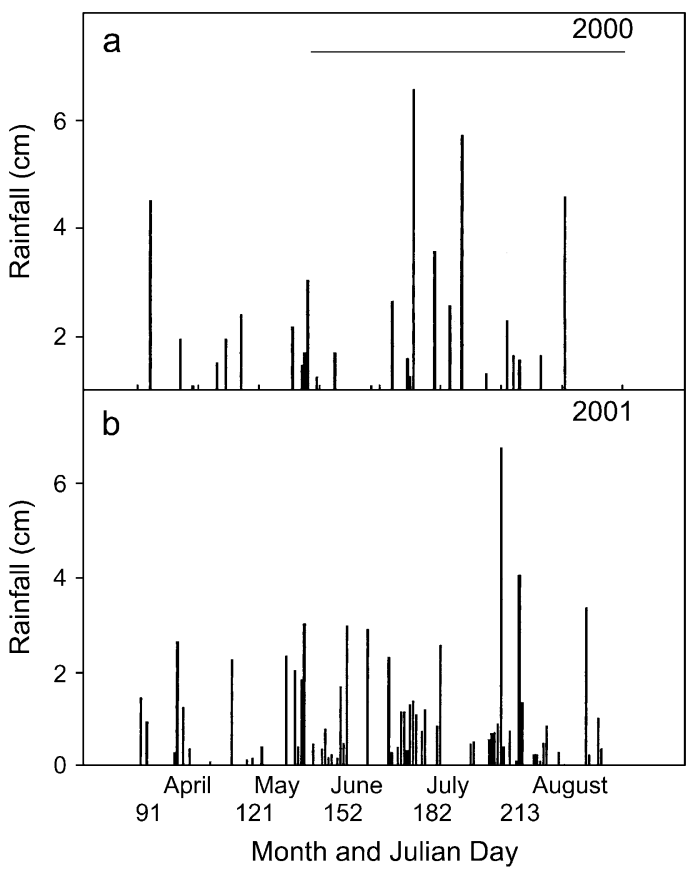

Fig. 2. Rainfall data for Waterville, NC, for 2000 and 2001. Values are daily precipitation from April to August. Waterville station is $12 \mathrm{~km}$ away from and $1085 \mathrm{~m}$ lower than Mt. Sterling Gap. Horizontal bar indicates time of year when foliar surveys were conducted.

2000. Less than $80 \%$ of insensitive individuals in 2000 , and $50 \%$ in 2001, were symptomatic. The percent of leaves exhibiting injury (Fig. 3c,d) followed a similar pattern as that for percent symptomatic individuals, with the exception that insensitive individuals in 2001 had very few symptomatic leaves. The percent symptomatic leaves for sensitive individuals was similar between years $(51 \%$ and $58 \%$ in 2000 and 2001, respectively) while the percent of injured leaves for insensitive individuals was slightly lower in 2000 (41\%), and much lower in 2001 (9\%).

Percent leaf loss for sensitive individuals was greater in 2000 than in 2001, while the opposite was true for insensitive individuals (Fig. 3e,f). As a result, there were no differences in the percent leaf loss between sensitive and insensitive individuals in 2001 (Fig. 3f).

\subsection{Leaf set responses}

Levels of stippling (purpling) were generally so low that logistic models could not accurately predict probability of injury. Only the oldest leaves in the sensitive plants had more injury (up to 28\%) than the other leaf positions (less than $15 \%$ ), and the other leaf positions did not differ among themselves (Souza, 2003). Using logistic regression analysis we were able to predict the probability of chlorosis and leaf loss. During model development, it was found that leaf position was highly correlated with leaf cohort, but that cohort generally was the better predictor.

Changes in chlorosis through time for every leaf cohort (symptomatic and asymptomatic leaves included) are shown 


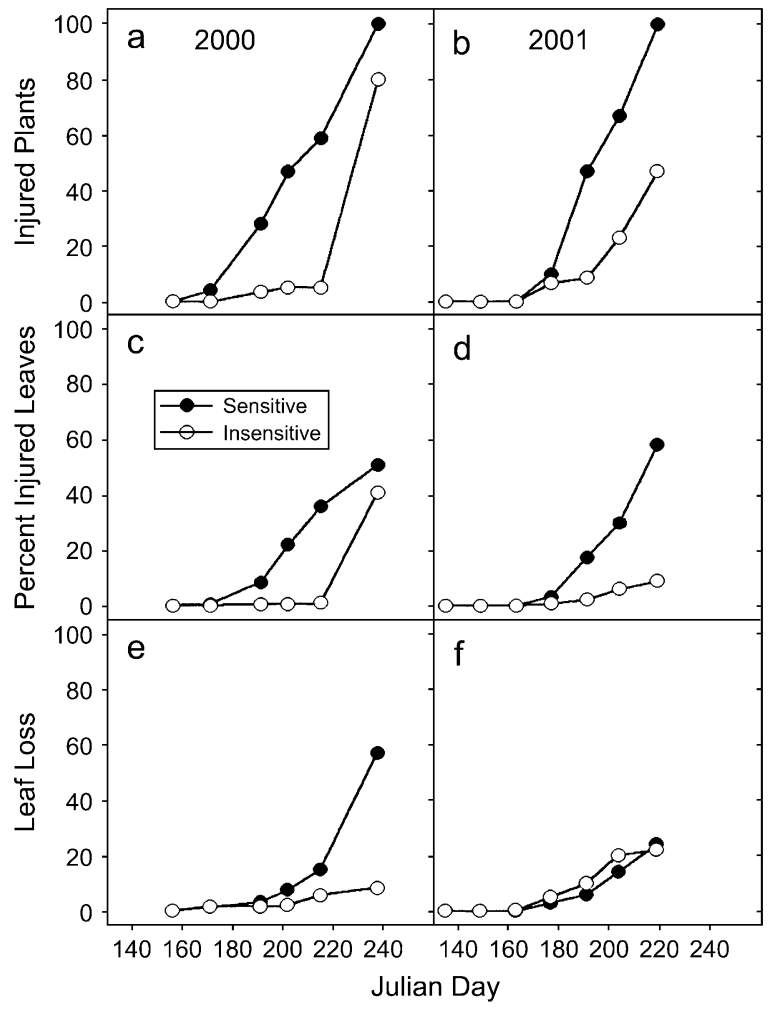

Fig. 3. Percent injured plants (a,b), injured leaves (c,d), and leaf loss (e,f) of ozone sensitive and insensitive plants versus Julian day for 2000 and 2001. A total of 95 plants were surveyed each year.

in Fig. 4. Both cohort $(p=0.001)$ and season $(p<0.001)$ were significant predictors of whether a leaf would have either low or high amounts of chlorosis. By the end of the 2000 season, the oldest leaf cohort (cohort 1$)$ was $\sim 6 \times(p=0.001)$ as likely to be in the high injury class than cohort 3 , and the next oldest cohort (cohort 2 ) was $\sim 4.5 \times$ as likely $(p<0.001$ ). Injury levels were too low in the remaining leaf sets to be predicted by the regression analysis. In 2001, the mean percent chlorotic leaf area was $17 \pm 4.1 \%$ for leaf cohort 1 (Fig. 4b), $15 \pm 3.3 \%$ for leaf cohort 2 , followed closely by leaf cohort 3 at $9.4 \pm 2.6 \%$. At the end of 2001 , leaf cohort 1 was $\sim 6 \times$ $(p=0.004)$, and the next oldest cohort was $\sim 2.4 \times$ ( $p=0.11)$ more likely, to be in the high injury class than cohort 3. Nonetheless, the threshold values for the SUM00 necessary to elicit visible injury for the three leaf cohorts in sensitive tall milkweed individuals in both years were approximately $60 \mathrm{ppm} \mathrm{h}$, whereas for insensitive individuals the threshold was approximately $90 \mathrm{ppm} \mathrm{h}$ (see Table 2).

The percent leaf loss of sensitive vs. insensitive plants at the end of 2000 and 2001 by leaf position is presented in Fig. 5. In both years, lower leaves were lost more frequently than upper leaves in both classes of plants (Fig. 5). Percent leaf loss was lower for sensitive individuals in 2001 than 2000 (Fig. 5a,c), while the opposite was true for insensitive individuals (Fig. 5b,d). Ozone-sensitive individuals lost leaves at the same rate in both years. The best model (categorized 0 for no leaf loss and 1 for at least one leaf lost) yielded different predictor variables each year. For instance, in 2000, leaf cohort $(p=0.013)$ and ozone $(p<0.001)$ were significant predictor variables for leaf loss. Leaf cohorts 1 and 2 were $2.6 \times$ $(p=0.004)$ and $1.8 \times(p=0.047)$, respectively, more likely to have lost a leaf when compared to cohort 3 (Fig. 6). In addition, leaf loss of at least one leaf was $2.2 \times(p<$ $0.001)$ more likely for every $100 \mathrm{ppm} \mathrm{h}$ increase in the SUM00. In 2001, leaf position $(p<0.001)$ and ozone $(p<0.001)$ were the significant predictor variables for the model. Leaf position 2 (and marginally 1) were $2.0 \times$ $(p=0.064)$ to $3.9 \times(p<0.001)$ more likely to have more than one leaf lost than leaf position 4 (Fig. 5). Leaf positions

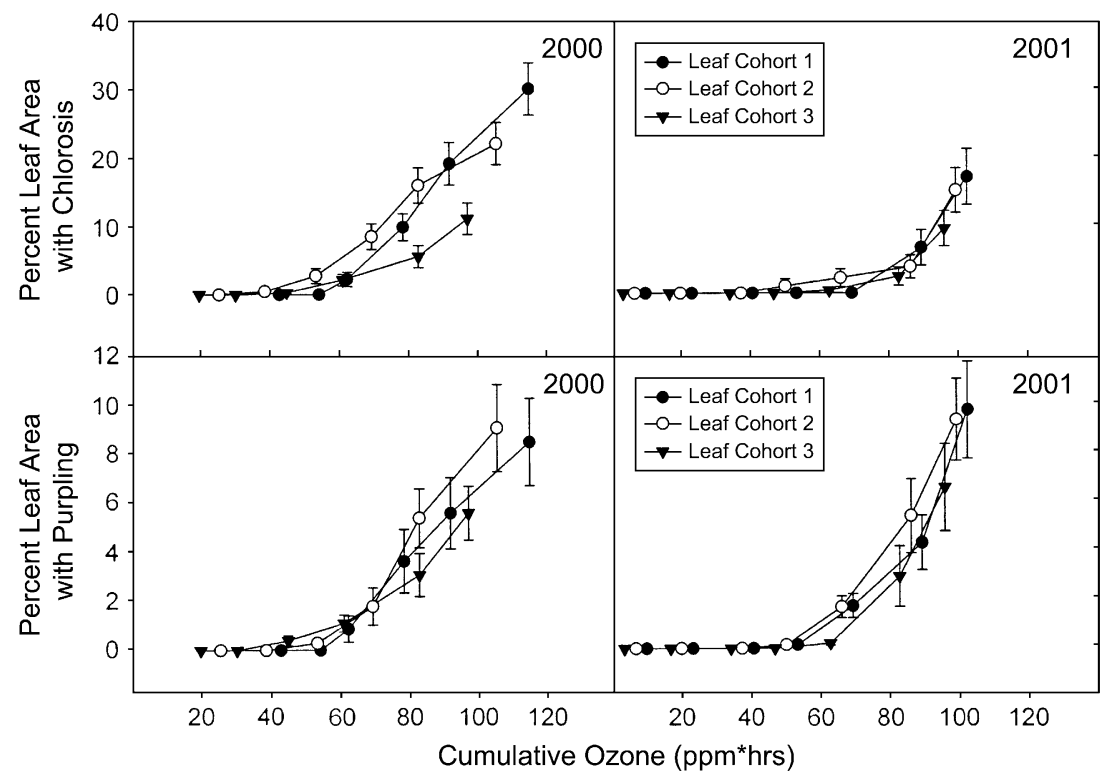

Fig. 4. Percent leaf area with chlorosis (all leaves, top panels) and purpling (bottom panels) for ozone sensitive plants at each leaf cohort versus cumulative ozone. Leaf cohort 1, oldest; leaf cohort 3 , youngest. Values are mean $\pm \mathrm{SE}, N=90-130$. 
Table 2

Ozone exposure thresholds for the development of foliar symptoms on sensitive and insensitive leaf cohorts for tall milkweed in 2000 and 2001

\begin{tabular}{llllll}
\hline Leaf cohort & \multicolumn{2}{l}{ SUM00 $(\mathrm{ppm} \mathrm{h})$} & & \\
\cline { 2 - 3 } & \multicolumn{2}{l}{ Sensitive } & & \multicolumn{2}{l}{ Insensitive } \\
\cline { 2 - 3 } & 2000 & 2001 & & 2000 & 2001 \\
\hline 1 & 62.3 & 69.4 & 89.4 & 91.9 \\
2 & 53.3 & 50.2 & & 86.2 & 82.9 \\
3 & 61 & 62.9 & 82.9 & 82.9 \\
\hline
\end{tabular}

Cohort 1 is oldest, while 2 and 3 are consecutively younger cohorts.

3 and 4 did not experience different losses $(p>0.05)$, nor could leaf positions 1 and 2 be distinguished. Nonetheless, positions 3 and 4 experienced leaf loss rates less than those for leaf positions 1 or 2 .

\section{Discussion}

The proportion of tall milkweed classified as sensitive in this study $(\sim 75 \%)$ was similar to that found by Chappelka et al. (1997), suggesting there has been little selection pressure towards more insensitive individuals over the past 7 years at this site. Our finding is not unexpected, given that over such a short time period ozone may not be a strong enough selective pressure to eliminate long-lived perennial plants, as has been found with annual plants (Reiling and Davison, 1992). In fact, due to the stochastic nature of ozone exposures at this site, where they may be high one year and low the next, it is likely that these sensitive genotypes are able to persist in the population despite their greater degree of ozone-induced foliar injury (Berrang et al., 1991). In addition, perennial plants may be buffered against short-term ozone-induced resource limitations by using stored carbohydrates in their rhizomes.

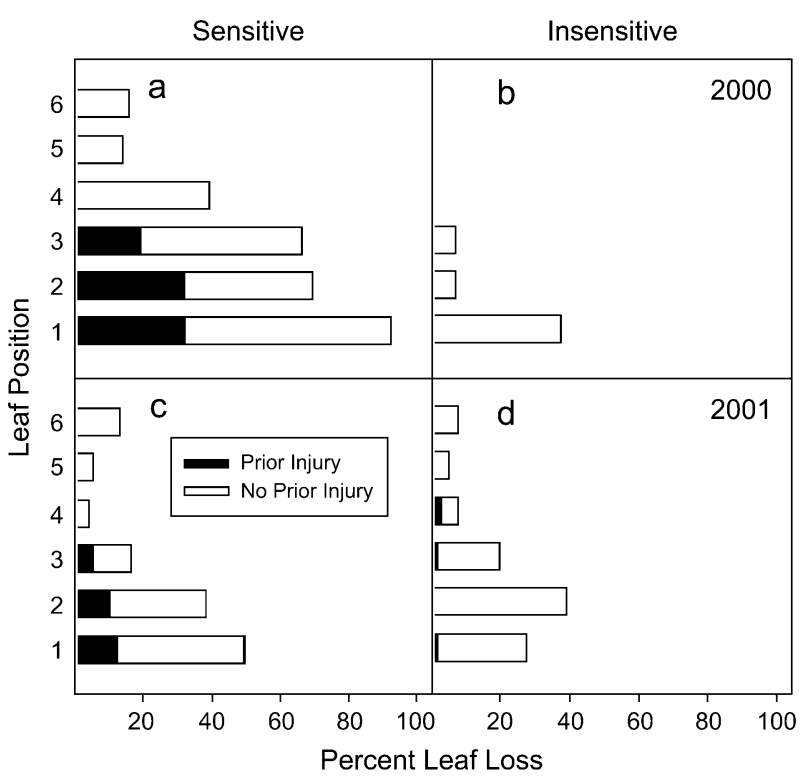

Fig. 5. Percent leaf loss for ozone sensitive (a,c) and insensitive (b,d) plants in August of 2000 and 2001 at each leaf position. Leaf 1, oldest; leaf 6, youngest. $N=216-392$

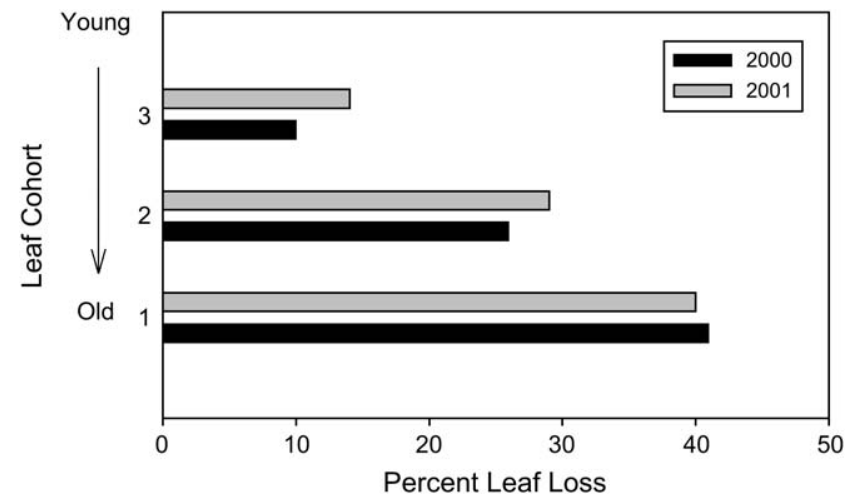

Fig. 6. Percent leaf loss in 2000 and 2001 by leaf cohort for ozone sensitive plants. $N=90-130$.

In fact, in the understory, tall milkweed seems to allocate less resources towards reproduction (i.e. flowering and ultimately seed set) and more towards vegetative growth (personal observation).

We found no differences in height between sensitivity types in either year of our study, in contradiction to the findings of Chappelka et al. (1997). This discrepancy may be due to the fact that Chappelka et al. included individuals from other populations within the Park in their calculations.

Ozone-induced foliar injury was observed earlier, and increased more rapidly, for ozone-sensitive individuals as compared to insensitive ones. The correlation between sensitivity and the early appearance of ozone-induced foliar injury has been found by others (VanderHeyden et al., 2001). However, the study by VanderHeyden et al. (2001) was conducted in controlled exposure systems, while ours is one of the first to document this phenological pattern in the field under ambient ozone exposure conditions. Relatively moderate exposures were needed to elicit ozone-induced foliar injury, explaining why injury often occurred in July, and not earlier, and thresholds for both chlorosis and stippling were similar for sensitive plants in both 2000 and 2001. For sensitive plants, a SUM00 of around $60 \mathrm{ppm} \mathrm{h}$ was required to elicit visible symptoms in both 2000 and 2001, while for insensitive plants the threshold was nearly 90 ppm h.

Few longitudinal studies have documented the progression of ozone-induced foliar injury on leaves at different positions on a plant throughout a season. Because leaf position and age (i.e., also exposure) are confounded, it is difficult to separate their influence on leaf sensitivity to ozone. Older (basal) leaves developed more injury over the season, particularly for chlorosis, in both years compared with younger (upper) leaves (Figs. 4 and 5), a pattern common to many other studies (Fujinuma et al., 1988; Karlsson et al., 1995; Chappelka et al., 2003), although Paakkonen et al. (1997) found just the opposite for Betula pendula Roth. Much of this pattern simply results from a longer exposure period for older leaves, and was made clearer in our study when we plotted injury as a function of leaf age rather than leaf position (Fig. 6), since leaves at any one position were of several different ages due to phenological differences among plants. 
Ozone sensitivity does depend on the physiological maturity of the leaf, and the greatest symptom development would result if high ozone concentrations occurred at times of maximum physiological sensitivity. The generally accepted hypothesis is that leaves reach their maximum sensitivity to ozone at about the same time as they reach maturity (Olszyk and Tibbitts, 1981). Changes during leaf ontogeny in stomatal conductance, biochemical defensive mechanisms, and anatomy most likely account for this widely reported pattern. For example, Olszyk and Tibbitts (1981) found that stomata of expanding leaves of Pisum sativum L. closed when exposed to ozone, while fully expanded leaves failed to do the same, resulting in more uptake of ozone by the mature leaves. On the other hand, Davison (unpublished data) found no intrinsic differences in stomatal conductance of ozone-sensitive and insensitive genotypes of Rudbeckia laciniata L., but as injury developed, stomatal conductance was lowered. Finally, as leaves mature, the amount of internal leaf air spaces tends to increase (James et al., 1999), which may facilitate the diffusion of ozone to the mesophyll cells, thereby resulting in greater injury (Plochl et al., 2000).

Within either sensitivity type there were no differences among leaf cohorts in the threshold SUM00 necessary to elicit foliar symptoms, nor in the amount of injury at any particular SUM00 later in the season. Leaf age alone is the best predictor of potential ozone-induced foliar injury, and subsequent injury development does not interact with stem position. Most leaves were physiologically mature by mid-June, prior to the appearance of any visible symptoms, and the development of ozoneinduced foliar injury in July and August would therefore not have been confounded by developmental changes in leaf structure. Leaves produced later in the season may experience greater vapor pressure deficits and increased drought stress, which may affect their physiological development (Patterson et al., 2000) and sensitivity to ozone (McLaughlin et al., 1982; Balls et al., 1996; Bungener et al., 1999; Ribas et al., 1998). However, no differences were notable among cohorts in the degree of injury with respect to the SUM00, suggesting that these effects were not important in this study (Fig. 6).

Ozone-induced foliar injury was more pronounced in 2000 than in 2001. This difference could be attributed to lower ozone uptake in 2001, due perhaps to a slightly lower ozone exposure, although the SUM00 index for 2001 was only $9 \%$ less than that in 2000. Rainfall was 12\% less in 2001 and there were eight periods with six or more days between rainfall events compared to the wetter season of 2000. Lower ozone exposure and rainfall may have resulted in increased drought stress on the plants, which could have lowered stomatal conductances and reduced ozone uptake (Kolb et al., 1997; Reich, 1987), thereby protecting plants from ozone that year (Bungener et al., 1999; Lee et al., 1999).

The observed levels of leaf loss in this study suggest that leaf senescence may be substantially accelerated in tall milkweed plants growing in the field. More than half of the leaves that fell off had no a priori injury consistent with exposure to ozone. Neufeld et al. (1992) showed that potted tall milkweed plants exposed to ozone in open-top chambers had substantial leaf loss during the growing season compared to plants in charcoal-filtered chambers. Other researchers have reported accelerated leaf loss without visible injury in a variety of plant species (Keller, 1988; Reiling and Davison, 1992; Wiltshire et al., 1993; Bergmann et al., 1995; Braun and Fluckiger, 1995; Pell et al., 1999; Back et al., 1999; Drogoudi and Ashmore, 2000). Most of the tall milkweed leaves had completely abscised by the end of August or early September, despite relatively mild weather conditions at the end of the season, and before many of the other understory or overstory plants.

In conclusion, ozone caused significant amounts of foliar injury on tall milkweed plants in Great Smoky Mountains National Park, and was most severe on older, lower leaves. Approximately $75 \%$ of the individuals were classified as sensitive, i.e., they had $>25 \%$ injury on symptomatic leaves. Within each sensitivity class though, there were no differences in the percent leaf area injured as a function of cumulative exposure, i.e., the SUM00 exposure. In addition, the threshold values for the SUM00 necessary to elicit visible injury did not differ between leaf cohorts or years in sensitive individuals. Ozone did appear to cause premature leaf loss, with more than half the leaves falling off without prior evidence of either ozone-induced chlorosis or stippling. Failure to take this into account could lead to underestimations of the impacts of ozone on tall milkweed in the field.

\section{Acknowledgements}

We thank Efrem Roberts, Brandon Scarborough, Seth Peoples, Corrie Williams, William Farrell, Rita Amaral, Tiago Souza, Angela Detweiler, Shay Dumas, Bia Yordi and Jazmin Varela for field assistance. Dr Ann Reed, in the Statistics Department at the University of Tennessee, provided invaluable statistical consulting, for which we are grateful. This work also could not have taken place without the assistance of Jim Renfro in Great Smoky Mountains National Park, Dr John D. Ray and Dave Joseph of the Air Resources Division of the National Park Service. We gratefully acknowledge the support of this work by grants from the Department of Biology, Graduate Student Senate and Cratis D. Williams Graduate School at Appalachian State University. The support of the National Geographic Society is also gratefully acknowledged.

\section{References}

Anderson, R.L., Brown, H.D., Chevone, B.I., McCartney, T.C., 1988. Occurrence of air pollution symptoms (needle tip necrosis and chlorotic mottling) on eastern white pine in Southern Appalachian Mountains. Plant Disease 72, 130-132.

Agresti, A., 1996. Multicategory logistic models. In: Agresti, A. (Ed.), An Introduction to Categorical Data Analysis. John Wiley \& Sons, New York, p. 290.

Balls, G.R., Palmer-Brown, D., Sanders, G.E., 1996. Investigating microclimatic influences on ozone injury in clover (Trifolium subterraneum) using artificial neural networks. New Phytologist 132, 271-280.

Back, J., Vanderklein, D.W., Topa, M.A., 1999. Effects of elevated ozone on carbon dioxide uptake and leaf structure in sugar maple under two light environments. Plant Cell and Environment 22, 137-147. 
Bennett, J.P., Stolte, K.W., 1985. Using vegetation biomonitors to assess air pollution injury in national parks: milkweed survey. Natural Resources Report Series No. 85-1.

Bergmann, E., Bender, J., Weigel, H.J., 1995. Growth responses and foliar sensitivities of native herbaceous species to ozone exposures. Water, Air and Soil Pollution 85, 1437-1442.

Bergweiler, C.J., Manning, W.J., 1999. Inhibition of flowering and reproductive success in spreading dogbane (Apocynum androsaemifolium) by exposure to ambient ozone. Environmental Pollution 105, 333-339.

Berrang, P., Karnosky, D.F., Bennett, J.P., 1991. Natural selection for ozone tolerance in Populus tremuloides: an evaluation of nationwide trends. Canadian Journal Forest Research 21, 1091-1097.

Blum, O., Bytnerowicz, A., Manning, W., Popovicheva, L., 1997. Ambient tropospheric ozone in the Ukrainian Carpathian mountains and Kiev region: detection with passive samplers and bioindicator plants. Environmental Pollution 98, 299-304.

Braun, S., Fluckiger, W., 1995. Effects of ambient ozone on seedlings of Fagus sylvatica L. and Picea abies (L.) Karst. New Phytologist 129, 33-44.

Bungener, P., Balls, G.R., Nussbaum, S., Geissmann, M., Grub, A., Fuhrer, J., 1999. Leaf injury characteristics of grassland species exposed to ozone in relation to soil moisture condition and vapour pressure deficit. New Phytologist 142, 271-282.

Chameides, W.J., Cowling, E.B., 1995. The state of the Southern Oxidant Study (SOS): policy-relevant findings in ozone pollution research 19881994. Southern Oxidant Study. College of Forest Resources, NC State University, Raleigh, NC, 94 pp.

Chappelka, A.H., Renfro, J.R., Somers, G., Nash, B., 1997. Evaluation of ozone injury on foliage of black cherry (Prunus serotina) and tall milkweed (Asclepias exaltata) in Great Smoky Mountains National Park. Environmental Pollution 95, 13-18.

Chappelka, A.H., Neufeld, H.S., Davison, A.W., Somers, G.L., Renfro, J.R., 2003. Ozone injury on cutleaf coneflower (Rudbeckia laciniata) and crown-beard (Verbesina occidentalis) in Great Smoky Mountains National Park. Environmental Pollution 125, 53-59.

Dattore, R.E., Gebhart, K.A., Malm, W.C., Flores, M., 1991. Use of an atmospheric trajectory model to explore the source regions affecting ozone concentrations at five eastern U.S. national parks. Air and Waste Management Association. 84th Annual Meeting and Exhibition, Vancouver, British Columbia. 91-66.7, 25 pp.

Department of the Interior, 1982. Preliminary certification of no adverse impact on Theodore Roosevelt Park and Lostwood National Wildlife Refuge under Section 165(d)(2)(C)iii of the Clean Air Act. Federal Registry 47 (133), 3022-3024.

Drogoudi, P.D., Ashmore, M.R., 2000. Does elevated ozone have differing effects in flowering and deblossomed strawberry? New Phytologist 147, 561-569.

Fujinuma, Y., Furukawa, A., Aiga, I., 1988. Effect of ozone on stomatal conductance in sunflower leaves: age-dependent inhibition. Environment Control in Biology 26, 83-90.

Ghosh, S., Skelly, J.M., Innes, J.L., Skelly, L., 1998. Temporal development of visual ozone injury on the foliage of Prunus serotina - a statistical evaluation. Environmental Pollution 102, 287-300.

Heagle, A.S., Miller, J.E., Sherrill, D.E., 1994. A white clover system to estimate effects of tropospheric ozone on plants. Journal of Environmental Quality 23, 613-621.

Heagle, A.S., Miller, J.E., Chevone, B.I., Dreschel, T.W., Manning, W.J., McPool, P.M., Morrison, C.L., Neely, G.E., Rebbeck, J., 1995. Response of white clover indicator system to tropospheric ozone at eight locations in the United States. Water, Air and Soil Pollution 85, 1373-1378.

Hildebrand, E., Skelly, J.M., Fredericksen, T.S., 1996. Foliar response of ozone-sensitive hardwood tree species from 1991 to 1993 in the Shenandoah National Park, Virginia. Canadian Journal of Forest Research 26, 658-669.

Horsfall, J.G., Barratt, R.W., 1945. An improved grading system for measuring plant disease. Phytopathology 35, 655.

James, S.A., Smith, W.K., Vogelmann, T.C., 1999. Ontogenetic differences in mesophyll structure and chlorophyll distribution in Eucalyptus globulus spp. globulus (Myrtaceae). American Journal of Botany 86, 198-207.
Kang, D., Aneja, V.P., Zika, R.G., Farmer, C., Ray, J.D., 2001. Nonmethane hydrocarbons in the rural southeast United States national parks. Journal of Geophysical Research 106, 3133-3155.

Karlsson, G.P., Sellden, G., Skarbyk, L., Pleijel, H., 1995. Clover as an indicator plant for phytotoxic ozone concentrations: visible injury in relation to species, leaf age, and exposure dynamics. New Phytologist 129, 355-365.

Keller, T., 1988. Growth and premature leaf fall in American aspen as bioindicators for ozone. Environmental Pollution 52, 183-192.

Kolb, T.E., Matyssek, R., 1997. Limitations and perspectives about scaling ozone impacts on trees. Environmental Pollution 115, 373-393.

Koutrakis, P., Wolfson, J.M., Bunyaviroch, A., Froehlich, S.E., Hirano, K., Mulik, J.D., 1993. Measurement of ambient ozone using a nitrite-coated filter. Analytical Chemistry 65, 209-214.

Krupa, S.V., Manning, W.J., 1988. Atmospheric ozone: formation and effects on vegetation. Environmental Pollution 50, 101-137.

Lee, E.H., Tingey, D.T., Hogsett, W.E., 1991. Adjusting ambient ozone air quality indicators for missing values. In: 1991 Proceedings of the Business and Economics Section. American Statistical Association, American Statistical Association, Alexandria, VA, pp. 198-203.

Lee, J.C., Skelly, J.M., Steiner, K.C., Zhang, J.W., Savage, J.E., 1999. Foliar response of black cherry (Prunus serotina) clones to ambient ozone exposure in ventral Pennsylvania. Environmental Pollution 105, 325-331.

Manning, W.J., 1993. Bioindicator plants for assessment of air quality: general considerations and plant responses to ambient ozone. In: Proc. 86th Ann. Meet. Air and Waste Manage. Assoc., 13-18 June 1993, Denver, CO, preprint 93-WA80.01, 14 pp.

Manning, W.J., Godzik, B., Musselman, R., 2002. Potential bioindicator species for ambient ozone in forested mountain areas of central Europe. Environmental Pollution 119, 283-290.

McLaughlin, S.B., McConathy, R.K., Duvick, D., Mann, L.K., 1982. Effects of chronic air pollution stress on photosynthesis carbon allocation and growth of white pine trees Pinus strobus. Forest Science 28, 60-70.

McLaughlin, S.B., Downing, D.J., 1985. Effects of air pollutants on forests: a critical review. Journal of Air Pollution Control Association 35, 516-534.

Mueller, S.F., 1994. Characterization of ambient ozone levels in Great Smoky Mountains National Park. Journal of Applied Meteorology 33, 465-472.

National Climatic Data Center, 2003. < http://www.ncdc.noaa.gov>.

National Research Council, 1991. Rethinking the Ozone Problem in Urban and Regional Air Pollution. National Academy Press, Washington, DC, $500 \mathrm{pp}$.

Neufeld, H.S., Renfro, J.R., Hacker, W.D., Silsbee, D., 1992. Ozone in Great Smoky Mountains National Park: dynamics and effects on plants. In: Berglund, R.D. (Ed.), Tropospheric Ozone and the Environment II. Air and Waste Management Association, Pittsburgh, PA, pp. 594-617.

Olszyk, D.M., Tibbitts, T.W., 1981. Stomatal responses and leaf injury in Pisum sativum cultivar Alsweet with sulfur dioxide and ozone exposures 1. Influence of pollutant level and leaf maturity. Plant Physiology 67, 539-544.

Pääkkonen, E., Holopainen, T., Kärenlampi, L., 1997. Variation in ozone sensitivity among clones of Betula pendula and Betula pubescens. Environmental Pollution 95, 37-44.

Patterson, M.C., Samuelson, L., Somers, G., Mays, A., 2000. Environmental control of stomatal conductance in forest trees of the Great Smoky Mountains National Park. Environmental Pollution 110, 225-233.

Pell, E.J., Sinn, J.P., Brendley, B.W., Samuelson, L., Vinten-Johansen, C., Tien, M., Skillman, J., 1999. Differential response of four tree species to ozone-induced acceleration of foliar senescence. Plant Cell and Environment 22, 779-790.

Plochl, M., Lyons, T., Ollerenshaw, J., Barnes, J., 2000. Simulating ozone detoxification in the leaf apoplast through direct reaction with ascorbate. Planta 210, 454-467.

Reich, P.B., 1987. Quantifying plant responses to ozone: a unifying theory. Tree Physiology 3, 63-91.

Reiling, K., Davison, A.W., 1992. Effects of a short ozone exposure given at different stages of development of Plantago major L. New Phytologist $121,29-37$. 
Ribas, A., Filella, I., Gimeno, B.S., Peñuelas, J., 1998. Evaluation of tobacco cultivars as bioindicators and biomonitors of ozone phytotoxic levels in Catalonia. Water, Air and Soil Pollution 107, 347-365.

Shaver, C.L., Tonnessen, K.A., Maniero, T.G., 1994. Clearing the air at the Great Smoky Mountains National Park. Ecological Applications 4, 690-701.

Skelly, J.M., Savage, J.E., De-Bauer, M.L., Alvarado, D., 1997. Observations of ozone-induced foliar injury on black cherry (Prunus serotina, var. capuli) within the Desierto de Los Leones National Park, Mexico City. Environmental Pollution 95, 155-158.

Souza, L., 2003. Seasonal development of ozone-induce foliar injury on tall milkweed (Asclepias exaltata) in Great Smoky Mountains National Park. MS thesis, Appalachian State University, Boone, NC, 75 pp.

Yuska, D.E., Skelly, J.M., Ferdinand, J.A., Stevenson, R.E., Savage, J.E., Mulik, J.D., Hines, A., 2003. Use of bioindicators and passive sampling devices to evaluate ambient ozone concentrations in north central Pennsylvania. Environmental Pollution 125, 71-80.
US EPA, 1996. Air Quality Criteria for Ozone and Other Photochemical Oxidants, vol. II. EPA-600/P-93/00bF. US EPA, National Center for Environmental Assessment. Research/Triangle Park, NC.

US EPA, 2001. Latest finds on national air quality: 2000 status and trends. EPA/454/K-01-002. Office of Air Quality, Planning and Standards, United States Environmental Protection Agency, Research Triangle Park, NC.

USDA. 2003. http://plants.usda.gov/plants/.

VanderHeyden, D., Skelly, J., Innes, J., Hug, C., Zhang, J., Landolt, W., Bleuler, P., 2001. Ozone exposure thresholds and foliar injury on forest plants in Switzerland. Environmental Pollution 111, 321-331.

Wiltshire, J.J.J., Wright, C.J., Colls, J.J., Unsworth, M.H., Craigon, J., 1993. The effect of ozone episodes on autumn leaf fall in apple. New Phytologist 124, 433-437.

Whittaker, R.H., 1956. The vegetation of the Great Smoky Mountains. Ecological Monographs 26, 1-80. 